\title{
METODE PERKUATAN KOLOM BETON PASCA GEMPA MENGGUNAKAN GFRP DAN CFRP
}

\author{
Parmo \\ Jurusan Teknologi, Fakultas Sains \& Teknologi UIN Sunan Ampel Surabaya \\ Email:parmo_99@uinsby.ac.id
}

\begin{abstract}
Abstrak
Bencana alam gempa bumi seringkali terjadi, terutama pada kawasan yang menempati zona tektonik aktif dan daerah-daerah yang berada pada pertemuan lempeng bumi. Indonesia adalah salah satu negara yang rawan terhadap bencana alam gempa bumi, hal ini dikarenakan indonesia termasuk negara yang berada pada zona tektonik aktif dan berada pada jalur subduksi yakni pertemuan tiga lempeng besar yakni lempeng Eurasia, lempeng pasifik dan lempeng Australia.

Bahaya yang ditimbulkan akibat bencana alam gempa bumi terhadap bangunan gedung miliputi kerusakan mulai dari tingkat ringan, sedang dan berat. Kerusakan yang ditimbulkan oleh gempa bumi dipengaruhi oleh beberapa faktor antara lain: kekuatan gempa, letak hiposentrum, struktur tanah dan struktur bangunan. Kerusakan pada struktur bangunan dapat disebabkan karena bangunan tersebut tidak direncanakan untuk menahan beban gempa atau sudah direncanakan mampu menahan beban gempa namun akibat adanya perubahan peta gempa mengakibatkan tingkat ketahanan terhadap gempa perlu dilakukan evaluasi dan perkuatan struktur.
\end{abstract}

Pada penelitian ini dilakukan perkuatan eksternal struktur kolom beton bertulang menggunakan GFRP dan CFRP. Dari hasil penelitian diperoleh peningkatan kapasitas lateral sebesar 143,95\% untuk kolom yang diberi perkuatan eksternal GFRP dan $152,15 \%$ untuk kolom yang diberi perkuatan eksternal CFRP.

Kata kunci: Gempa Bumi, Perkuatan Kolom, GFRP, CFRP.

\section{Pendahuluan}

Bencana alam gempa bumi seringkali terjadi, terutama pada kawasan yang menempati zona tektonik aktif dan daerah-daerah pertemuan antar lempeng bumi. Para ahli mencatat dan menyimpulkan bahwa $80 \%$ gempa bumi di dunia terletak di daerah subdaksi. Daerah-daerah pada perbatasan lempeng-lempeng tektonik aktif dan saling bertumbukan antar lempeng baik berupa tumbukan langsung (collision) maupun dalam bentuk menyusupnya lempeng plat satu kedalam lempeng plat yang lain (subduction) sering kali menjadi titik episenter gempa bumi (Pawirodikromo, W., 2012).

Wilayah Negara Kepulauan Republik Indonesia (NKRI) merupakan kawasan yang juga sering terjadi bencana alam gempa bumi. Data dari laman Badan Metereologi dan Geofisika menyebutkan bahwa $70-100$ kali aktifitas gempa bumi terjadi dalam setiap tahunnya dengan kekuatan diatas 5,5 SR. Hal ini disebabkan karena wilayah NKRI berada pada zona tektonik aktif dan pertemuan antara 3 (tiga) lempeng besar dunia yakni lempeng Eurasia, lempeng Pasifik dan lempeng Australia. Tingginya aktifitas 
Prosiding Seminar Nasional Aplikasi Teknologi Prasarana Wilayah IX (ATPW),

Surabaya, 02 Juni 2016, ISSN 2301-6752

gempa bumi dapat dilihat pada gambar di Indonesia periode $1973-2010$.

1 , data episenter aktifitas gempa bumi

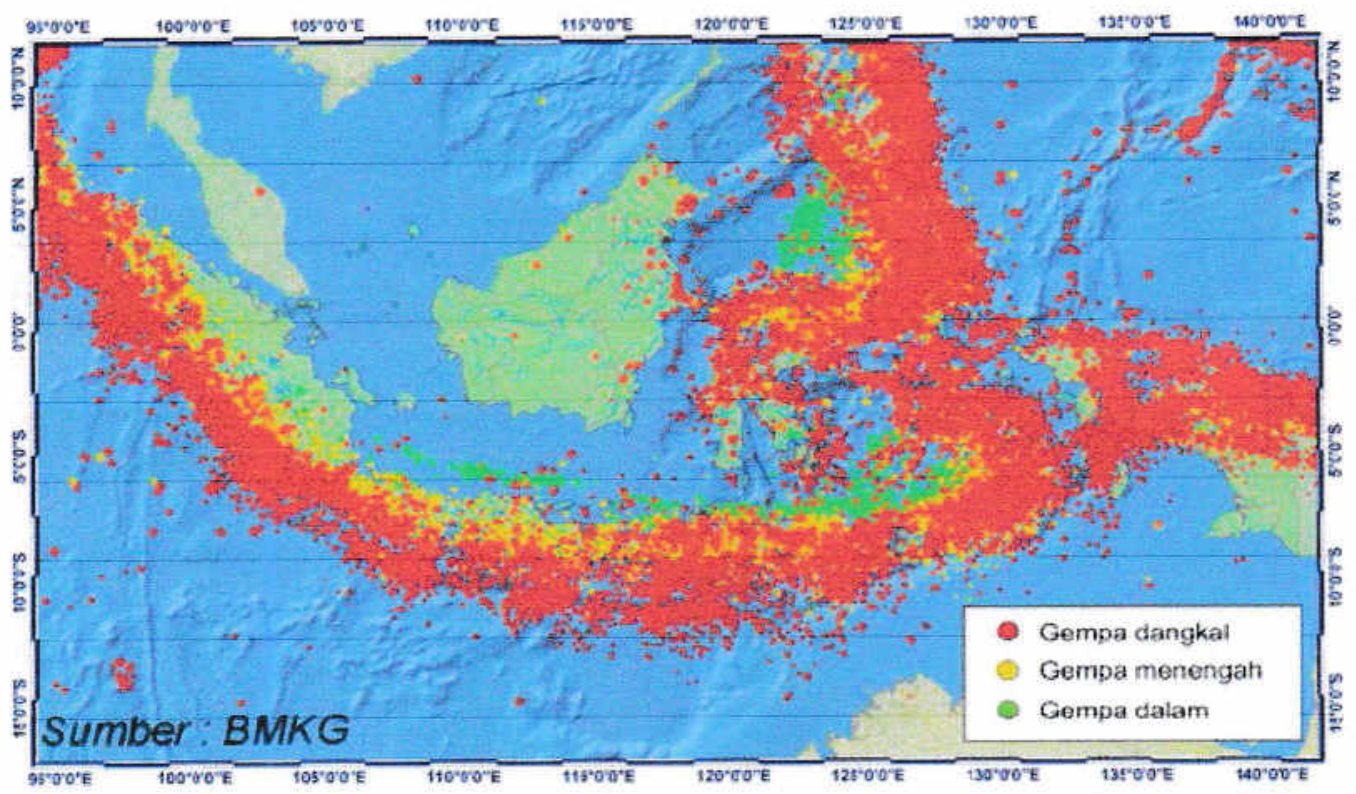

Gambar 1. Data episenter aktifitas gempa bumi di Indonesia periode 1973 - 2010

Bahaya yang ditimbulkan akibat bencana alam gempa bumi terhadap bangunan gedung meliputi kerusakan ringan, sedang dan berat. Faktor-faktor yang mempengaruhi tingkat kerusakan gedung akibat gempa bumi antara lain: kekuatan gempa, letak hiposentrum, struktur tanah dan struktur bangunan. Pada Pedoman Pemeriksaan Awal Kerusakan Bangunan Beton Bertulang Akibat Gempa (2004), tingkat kerusakan elemen struktur kolom dan balok diklasifikasikan dan dibuat rangking antara 1 sampai dengan 5, penambahan rangking dari 1 sampai dengan 5 menunjukkan penambahan tingkat kerusakan kolom dan balok beton bertulang. Tabel 1 menunjukkan kriteria rangking tingkat kerusakan komponen kolom dan balok struktur bangunan.

Menurut United State Geological Survey (2005) tingkat gempa dibagi dengan menghubungkan dampak gempa bumi dan jumlah kejadiaanya sebagaimana ditunjukkan pada tabel 2 .

Tabel 1. Kriteria Rangking Tingkat Kerusakan Komponen Kolom dan Balok

\begin{tabular}{cl}
\hline $\begin{array}{c}\text { Rangking } \\
\text { Kerusakan }\end{array}$ & \multicolumn{1}{c}{ Deskripsi Kerusakan Komponen Struktur } \\
\hline 1 & - Retak rambut dapat terlihat pada permukaan beton (lebar retak $<0.2 \mathrm{~mm}$ ) \\
2 & - Retak dapat terlihat jelas pada permukaan beton (lebar retakan kira-kira \\
& $0.2-1.0 \mathrm{~mm}$ ) \\
3 & - Kehancuran lokal pada selimut beton \\
4 & - Retakan yang sangat jelas (lebar retakan kira-kira 1-2 mm) \\
& Kehancuran beton sangat nyata dengan tulangan beton terlihat
\end{tabular}


Prosiding Seminar Nasional Aplikasi Teknologi Prasarana Wilayah IX (ATPW), Surabaya, 02 Juni 2016, ISSN 2301-6752

\begin{tabular}{cll}
\hline $\begin{array}{c}\text { Rangking } \\
\text { Kerusakan }\end{array}$ & \multicolumn{1}{c}{ Deskripsi Kerusakan Komponen Struktur } \\
\hline & - Selimut beton hancur \\
& - Tulangan tertekuk \\
5 & - Inti penampang beton hancur \\
& - Deformasi vertikal pada kolom (dinding dapat terlihat) \\
& - Penurunan dan/atau kemiringan lantai dapat terlihat \\
\hline
\end{tabular}

(Sumber: Pedoman Pemeriksaan Awal Kerusakan Bangunan Beton Bertulang Akibat Gempa, Departemen Pekerjaan Umum, 2004)

Tabel 2. Hubungan kekuatan gempa bumi dan frekuensi kejadiaanya

\begin{tabular}{|c|c|c|c|}
\hline Penamaan & $\begin{array}{l}\text { Skala } \\
\text { Ritcher }\end{array}$ & Dampak Gempa Bumi & Jumlah Kejadian \\
\hline Mikro & $<2,0$ & Gempa bumi mikro, tak terasa & $8.000 /$ hari \\
\hline Sangat Minor & $2,0-2,9$ & $\begin{array}{c}\text { Umumnya tak terasa, tapi tercatat } \\
\text { peralatan }\end{array}$ & $1.000 /$ hari \\
\hline Minor & $3,0-3,9$ & $\begin{array}{c}\text { Umumnya terasa, jarang mengakibatkan } \\
\text { kerusakan }\end{array}$ & $49.000 /$ tahun \\
\hline Lemah & $4,0-4,9$ & $\begin{array}{c}\text { Teramati di dalam rumah, ada suara } \\
\text { berderik, tidak ada kerusakan }\end{array}$ & $6.200 /$ tahun \\
\hline Sedang & $5,0-5,9$ & $\begin{array}{l}\text { Kerusakan pada bangunan dengan } \\
\text { konstruksi buruk pada daerah yang tidak } \\
\text { luas. Bangunan dengan konstruksi baik } \\
\text { rusak sedikit }\end{array}$ & $8.000 /$ tahun \\
\hline Kuat & $6,0-6,9$ & $\begin{array}{l}\text { Dapat mengakibatkan kerusakan pada } \\
\text { daerah padat penduduk sepanjang } 150 \\
\mathrm{~km} 2\end{array}$ & $120 /$ tahun \\
\hline Sangat Kuat & $7,0-7,9$ & $\begin{array}{l}\text { Kerusakan pada daerah lebih dari } 150 \\
\text { km2 }\end{array}$ & $18 /$ tahun \\
\hline Besar & $8,0-8,9$ & $\begin{array}{c}\text { Kerusakan pada daerah lebih beberapa } \\
\text { ratus km }\end{array}$ & $1 /$ tahun \\
\hline Besar \& Langka & $>9,0$ & $\begin{array}{c}\text { Kerusakan pada daerah lebih beberapa } \\
\text { ratus km }\end{array}$ & $1 / 20$ tahun \\
\hline
\end{tabular}

Pada struktur bangunan yang mengalami kerusakan ringan hingga sedang akibat bencana alam gempa bumi masih memungkinkan untuk dilakukan perbaikan dan perkuatan. Tindakan perbaikan dan perkuatan serta restorasi ini sering disebut retrofitting. Retrofitting adalah upaya untuk mengembalikan dan meningkatkan kondisi struktur atau komponen struktur kepada kondisi semula bahkan lebih baik sehingga bangunan atau bagianbagiannya dapat lebih berfungsi lagi setelah dilakukan perbaikan dan perkuatan.

Kerusakan yang sering terjadi akibat gempa bumi ada beberapa macam tergantung kuat tidaknya energi gempa. Kerusakan pada bangunan akibat gempa bumi dapat berupa keretakan, spalling maupun keruntuhan struktur bangunan.

Metode perbaikan dan perkuatan komponen struktur pasca terjadinya kerusakan akibat gempa bumi dapat menggunakan metode injeksi untuk keretakan, patching dan grouting untuk mengatasi spalling dan bisa juga 
ditambahkan dengan perkuatan baik dengan cara concrete jacketing, steel plate bonding maupun dengan perkuatan eksternal Fiber Reinforced Polymer (FRP).

Pada penelitian ini perkuatan komponen struktur kolom digunakan material FRP berupa Glass Fiber Reinforced Polymer (GFRP) dan Carbon Fiber Reinforced Polymer (CFRP). Komponen struktur kolom dipilih karena kolom mempunyai peranan yang penting dalam konfigurasi struktur bangunan, kegagalan kolom akibat beban gempa mengakibatkan kegagalan sistem struktur secara keseluruhan dan menyebabkan bangunan menjadi runtuh. Untuk mensimulasikan keadaan gempa digunakan pembebanan lateral siklik.
Penggunaan material FRP untuk perkuatan kolom beton bertulang yang mengalami kerusakan akibat gempa dipilih karena memiliki keunggulan antara lain: bahan lebih ringan, kekuatan tarik tinggi, tidak terjadi korosi sehingga memiliki durabilitas (keawetan) yang baik, mudah dalam pemasangannya sehingga menghemat waktu serta bahannya mudah untuk dibentuk (fleksibel). Gambar 2 menunjukkan lembaran matrik CFRP dan GFRP. Material FRP lain yang sering digunakan untuk perkuatan struktur adalah Aramid Fiber Reinforced Polymer (AFRP), namun dari ketiga material FRP, AFRP lebih mahal dari sisi harga.

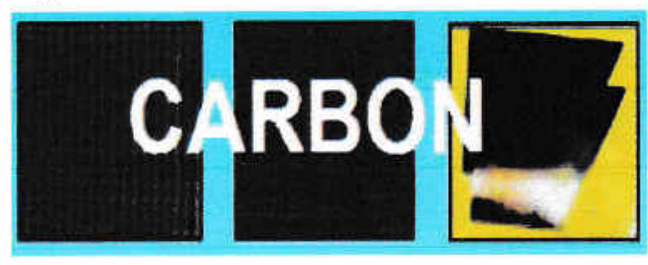

(a) CFRP

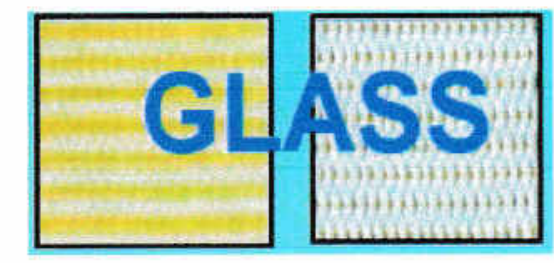

(b)GFRP

Gambar 2. Lembaran Matrik CFRP dan GFRP

\section{Metodologi}

Penelitian eksperimental dimulai dengan pengujian awal antara lain: pengujian tarik baja tulangan, pengujian tarik FRP dan uji tekan silinder beton. Dari hasil pengujian tarik baja tulangan diperoleh fy $=549,94 \mathrm{Mpa}$ dan fy $=$ 386,52 Mpa masing-masing untuk tulangan longitudinal D19 $\mathrm{mm}$ dan tulangan sengkang $\varnothing 10 \mathrm{~mm}$. Dari hasil pengujian tarik FRP diperoleh kuat tarik ultimate $\mathrm{Fu}=575 \mathrm{Mpa}$ dan $409,71 \mathrm{Mpa}$ masing-masing untuk material GFRP dan CFRP. Sedangkan dari hasil pengujian tekan beton didapatkan kuat tekan $\mathrm{fc}^{\prime}=20,34 \mathrm{Mpa}$ pada hari ke 47 umur beton. Hasil pengujian baja tulangan, pengujian FRP dan pengujian beton ditunjukkan pada tabel 3 , tabel 4 dan tabel 5 .

Tabel 3. Hasil uji tarik baja tulangan

\begin{tabular}{ccc}
\hline Material baja & Kuat leleh (Mpa) & Kuat Ultimit (Mpa) \\
\hline Tulangan ulir diameter $19 \mathrm{~mm}$ & 549,94 & 530,08 \\
Tulangan polos diameter $10 \mathrm{~mm}$ & 386,52 & 756,17 \\
\hline
\end{tabular}


Prosiding Seminar Nasional Aplikasi Teknologi Prasarana Wilayah IX (ATPW), Surabaya, 02 Juni 2016, ISSN 2301-6752

Tabel 4. Hasil uji tarik FRP

\begin{tabular}{ccccccccc}
\hline $\begin{array}{c}\text { Material Carbon } \\
\text { Composite }\end{array}$ & $\begin{array}{c}\mathrm{tb} \\
(\mathrm{mm})\end{array}$ & $\begin{array}{c}\mathrm{Lb} \\
(\mathrm{mm})\end{array}$ & $\begin{array}{c}\mathrm{Pj} \\
(\mathrm{mm})\end{array}$ & $\begin{array}{c}\mathrm{Pjs} \\
(\mathrm{mm})\end{array}$ & $\begin{array}{c}\mathrm{W} \\
(\mathrm{gr})\end{array}$ & $\mathrm{P}(\mathrm{N})$ & $\begin{array}{c}\text { Fu } \\
\left(\mathrm{N} / \mathrm{mm}^{2}\right)\end{array}$ & $\begin{array}{c}\text { Fu rata- } \\
\text { rata } \\
(\mathrm{MPa})\end{array}$ \\
\hline Benda uji 1 CFRP & 3,10 & 26,10 & 246,55 & 412 & 63 & 30500 & 376,96 & \\
Benda uji 2 CFRP & 3,25 & 25,87 & 247,70 & 410 & 60 & 31000 & 368,75 & 409,71 \\
Benda uji 3 CFRP & 2,70 & 24,90 & 245,50 & 413 & 58 & 32500 & 483,42 & \\
Benda uji 1 GFRP & 2,75 & 25,12 & 252,10 & 400 & 72 & 33000 & 477,77 & \\
Benda uji 2 GFRP & 2,80 & 25,42 & 245,00 & 394 & 70 & 35600 & 500,23 & 510,48 \\
Benda uji 3 GFRP & 2,77 & 26,45 & 242,60 & 393 & 73 & 40500 & 553,44 & \\
\hline
\end{tabular}

Keterangan :

$\mathrm{Tb}=$ Specimen Thickness

$\mathrm{Lb}=$ Specimen Width

$\mathrm{Pj}=$ Gauge Length

Pjs = Gauge Length + Tab Length

$\mathrm{W}=$ Weight

Tabel 5. Hasil uji tekan beton

\begin{tabular}{lccccccc}
\hline & \multicolumn{7}{c}{ Kuat Tekan Beton (Mpa) } \\
\cline { 2 - 7 } Deskripsi & Benda & Benda & Benda & Benda & Benda & Benda & Rata-rata \\
& Uji 1 & Uji 2 & Uji 3 & Uji 4 & Uji 5 & Uji 6 & \\
\hline Kuat Tekan Beton 7 hari & 12,11 & 12,39 & 12,56 & 13,41 & 11,71 & 12,73 & 12,48 \\
Kuat Tekan Beton 28 hari & 18,44 & 18,10 & 18,89 & 17,87 & 19,63 & 19,35 & 18,71 \\
Kuat Tekan Beton 47 hari & 22,29 & 22,12 & 21,55 & 21,33 & 21,49 & 20,65 & 20,34 \\
\hline
\end{tabular}

Specimen kolom uji berjumlah 3 (tiga) buah yang masing-masing berukuran $350 \times 350 \mathrm{~mm}$ dengan panjang $1100 \mathrm{~mm}$. Ke-3 benda uji tersebut masing-masing adalah 1 (satu) kolom kontrol tanpa perkuatan dan dilakukan pengujian aksial-siklik sampai hancur, 1 (satu) buah kolom retrofit GFRP dan 1 (satu) buah kolom retrofit CFRP. Masing-masing kolom retrofit (GFRP dan CFRP) mengalami 2 (dua) kali pengujian, pengujian pertama dilakukan dengan cara yang sama dengan pengujian kolom kontrol yakni dikenakan beban aksial konstan sebesar $748 \mathrm{KN}$ dan beban lateral siklik bervariasi menggunakan pola pembebanan displacement control dengan rasio drift semakin meningkat dimulai dari $\Delta / \mathrm{L}(\mathrm{x} 102): 0,2 ; 0,25$; 0,$35 ; 0,5 ; 0,75 ; 1,0$ dan seterusnya. Pada pengujian awal dan mengacu pada pengujian kolom kontrol, pengujian kolom retrofit dihentikan pada lateral drift $2,2 \%$ dimana kolom uji telah mengalami keretakan yang terlihat secara jelas dimana lebar retakan berkisar antara $1-2 \mathrm{~mm}$. Kondisi ini menggambarkan bahwa kolom retrofit mengalami kerusakan struktur akibat beban gempa pada tingkat kerusakan rangking/skala 3.

Selanjutnya kedua kolom retrofit dilakukan perbaikan dan perkuatan. Adapun perbaikan kolom retrofit diantaranya adalah dengan metode injeksi dan grouting. Perbaikan dengan metode injeksi diperlukan untuk memperbaiki kolom yang mengalami keretakan struktur. Material yang dipergunakan untuk injeksi adalah material epoxy yang mempunyai viskositas yang rendah sehingga dapat mengisi dan sekaligus melekatkan kembali bagian beton yang terpisah. 
Alat dan Bahan untuk persiapan injeksi yaitu Epoxy MC-Dur 1200 dan MC-Surfacepacker LP. Retakan pada benda uji diberi paku dengan jarak kurang lebih $15 \mathrm{~cm}$ peralur retakan yang terjadi, hal ini dimaksudkan untuk membuat celah tempat resin yang diinjeksikan agar masuk ke dalam retakan. Epoxy MC-Dur 1200 kemudian dioles sepanjang alur retakan. Kemudian nipel MC-Surfacepacker LP dipasang pada tempat paku yang ditanamkan pada beton. Setelah itu didiamkan selama kurang lebih 1 jam hingga epoxy mengeras. Sisa bahan epoxy ditempatkan pada suatu wadah tersendiri, dimana hal ini dimaksudkan untuk pengontrol terhadap kekerasan bahan epoxy yang teraplikasi pada benda uji.

Setelah epoxy mengeras, maka dengan menggunakan alat MCFastpack Power Tool dan Air
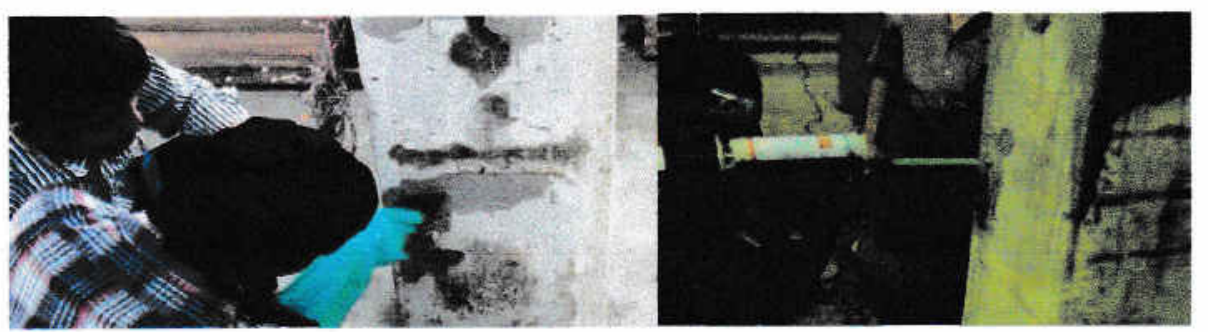

Gambar 3. Proses pelaksanaan metode perbaikan beton dengan injeksi

Pada beton yang mengalami spalling yakni di bagian atas (kepala) kolom akibat tekanan beban aksial dan gesekan alat uji dilakukan grouting. Grouting adalah metode perbaikan dengan melakukan pengecoran memakai bahan non-shrink mortar. Metode ini dilakukan secara manual (gravitasi) atau menggunakan pompa bertekanan. Pada metode perbaikan ini yang perlu diperhatikan adalah bekesting yang terpasang harus benarbenar kedap, agar tidak ada kebocoran spesi yang mengakibatkan terjadinya keropos dan harus kuat agar mampu
Compressor bahan resin MC-Fastpack 2700 diinjeksikan ke dalam retakan beton. Injeksi dihentikan setelah bahan resin meluber keluar melalui nipel. Penutup nipel MC-Surfacepacker LP harus dipasang sebelum berpindah ke titik injeksi berikutnya. Setelah titik terakhir injeksi dari benda uji selesai dilaksanakan, maka proses injeksi diulang sekali lagi. Hal ini dilakukan dikarenakan dengan viskositas yang rendah maka pada proses pertama resin akan mengisi celah-celah, sehingga proses injeksi harus dilakukan kembali. Proses injeksi yang kedua dilakukan sama dengan proses pertama. Setelah keseluruhan proses selesai, maka benda uji didiamkan kurang lebih 24 jam dan siap untuk dilakukan proses retrofit dengan menggunakan FRP. Gambar 3 menunjukkan proses pelaksanaan metode perbaikan beton dengan injeksi. 
Sebelum dilapisi resin maka benda uji kolom beton harus dipastikan dalam kondisi bersih dan benar-benar kering. Lapisan pertama berupa lapisan tipis resin dioleskan pada benda uji, kemudian disiapkan FRP dengan panjang dan lebar sesuai dengan kebutuhan. Kemudian lembaran ini dipasangkan pada benda uji. Untuk memastikan tidak adanya gelembung udara yang terperangkap antara lembar FRP dan permukaan beton maka digunakan rol khusus. Rol ini akan memberikan tekanan pada resin sehingga menembus ke dalam serat. Rol terus menerus digunakan sampai permukaan serat jenuh yang mengindikasikan telah terjadi pembasahan secara total. Setelah itu dilakukan pemberian lapisan resin yang kedua pada permukaan kolom yang telah terbungkus oleh FRP. Untuk menghindari geser dan debonding maka digunakan overlap antar lapisan sepanjang $200 \mathrm{~mm}$. Gambar 4 menunjukkan proses pemasangan FRP.

Benda uji kolom yang terbungkus dibiarkan pada suhu kamar selama 4 hari untuk memastikan epoxy telah mengeras sebelum dilakukan pengujian siklik. Hal ini bertujuan untuk mendapatkan kekuatan penuh sebelum pengujian.

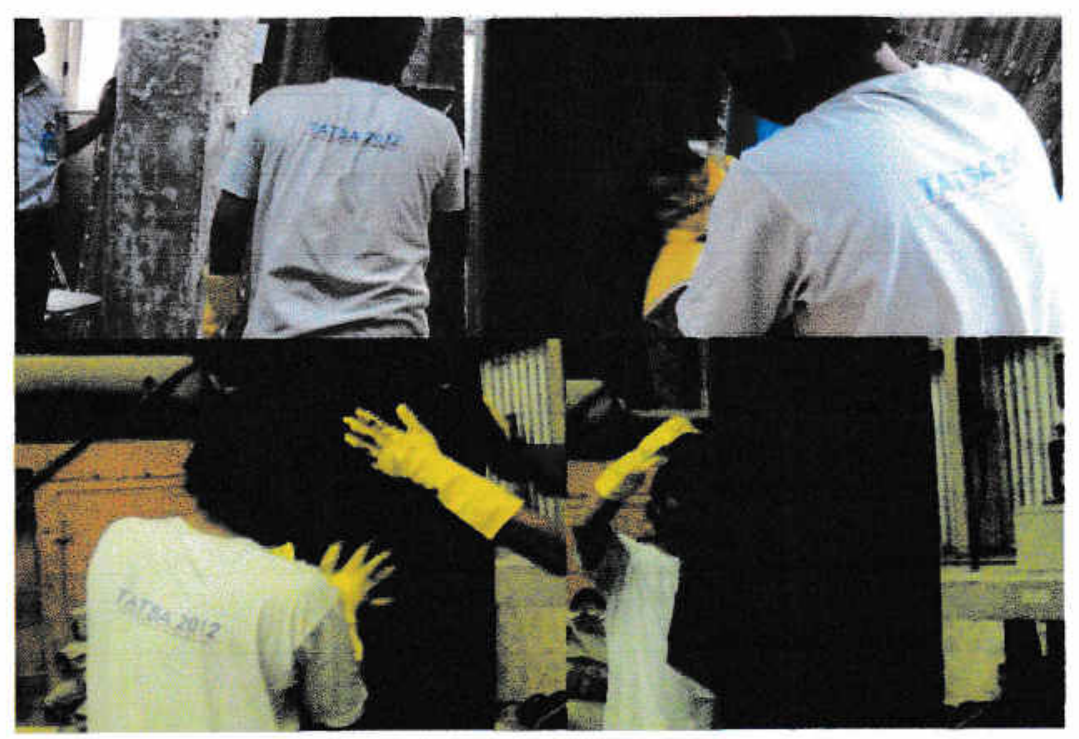

Gambar 4. Proses pemasangan FRP

Kolom yang telah di lakukan perbaikan dan perkuatan dengan GFRP maupun CFRP kemudian dilakukan pengujian. Prosedur pengujian sama dengan pengujian-pengujian sebelumnya sampai kedua kolom retrofit di uji sampai batas ultimate dan kolom mengalami keruntuhan.

Setting up pengujian kolom nampak pada gambar 5. Hasil pengujian berupa beban dan lendutan dicatat menggunakan strain meter. 


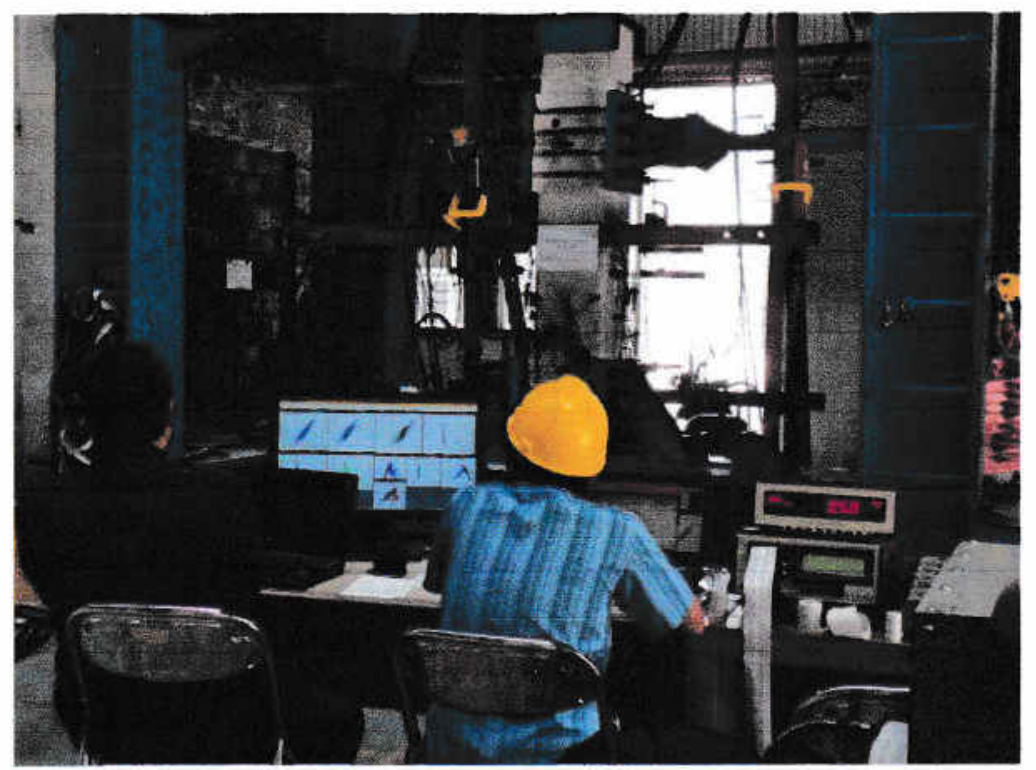

Gambar 5. Setting Up pengujian kolom

\section{Hasil dan pembahasan}

Pada kolom kontrol retak awal terjadi pada beban lateral sebesar 226,4 $\mathrm{kN}$ di drift rasio $1,4 \%$. Spalling kolom terjadi pada saat beban mencapai 250,1 $\mathrm{kN}$ drift rasio $2,75 \%$ yang menyebabkan tulangan longitudinal terlihat dengan jelas. $\mathrm{P}_{\text {maks }}$ terjadi pada beban lateral $288,0 \mathrm{kN}$ drift rasio $3,50 \%$. Kerusakan kolom paling parah terjadi pada zona sendi plastis sampai ketinggian $600 \mathrm{~mm}$ di atas penjepit (pondasi) kolom. Kegagalan diakibatkan spalling beton dan hancurnya inti beton serta tekuk tulangan longitudinal. Selain di zona sendi plastis, kerusakan juga terjadi pada kolom bagian atas, meskipun tidak sebesar pada zona sendi plastis. Kegagalan yang terjadi pada kontrol seperti ditampilkan pada gambar 6 .

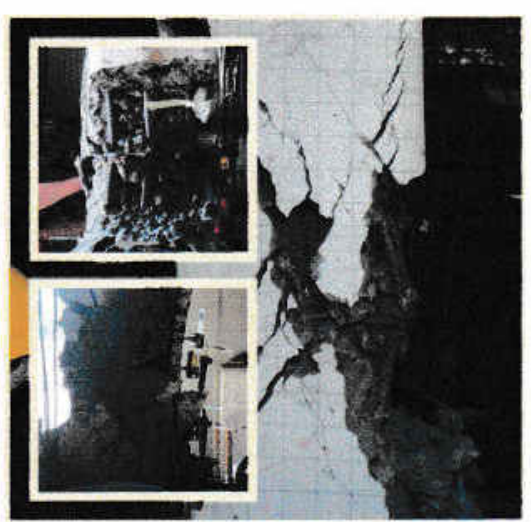

Gambar 6. Kerusakan kolom kontrol

Hasil pengujian kolom retrofit GFRP awal terjadi pada beban $-360,1 \mathrm{kN}$ dan drift ke $3,5 \%$, retak yang terjadi pada kolom ditandai dengan debonding antara GFRP dan beton serta robeknya fiber jacket. Spalling terjadi pada beban $-326,3 \mathrm{kN}$ di drift $5,5 \%$, pada saat terjadi spalling langsung diikuti keruntuhan kolom. $\mathrm{P}_{\text {maks }}$ terjadi pada beban $-414,6 \mathrm{kN}$ drift $5,0 \%$. Gambar 7 menunjukkan kerusakan kolom retrofit GFRP. 


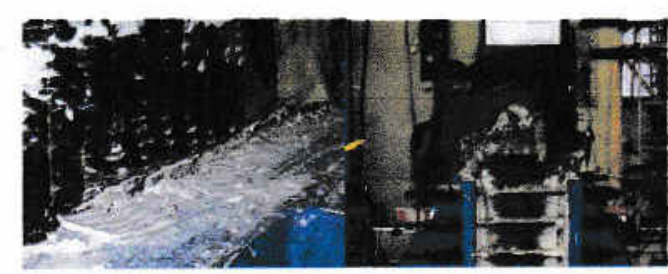

Gambar 7. Kerusakan kolom retrofit GFRP

Pada kolom retrofit CFRP retak awal terjadi di daerah sendi plastis diatas penjepit kolom pada step ke 686 , siklus kedua, drift rasio $2,75 \%$ dan beban lateral $370 \mathrm{KN}$. Keretakan ini terlihat dalam bentuk sobekan pada permukaan lapisan CFRP sepanjang $\pm 7 \mathrm{Cm}$. Pada step ke 728 siklus pertama drift rasio $3,50 \%$ dan beban lateral $373,6 \mathrm{KN}$ terlihat permukaan lapisan CFRP pada sisi kiri kolom (sisi yang berseberangan dengan aktuator) di daerah sendi plastis mulai menggelembung dan beberapa serat putus. Dan $\mathbf{P}_{\text {maks }}$ terjadi pada step ke 810 siklus ketiga drift rasio $5,40 \%$ dan beban lateral $438,2 \mathrm{KN}$ panjang gelembung pada permukaan CFRP sudah mencapai $10 \mathrm{Cm}$. Dan pada step ke 860 siklus pertama drift rasio $5,50 \%$ dan beban lateral $376,9 \mathrm{KN}$ permukaan daerah sendi plastis bagian belakang kolom sudah tidak rata, terjadi sobekkan dan selanjutnya hancur seperti pada gambar 8 .

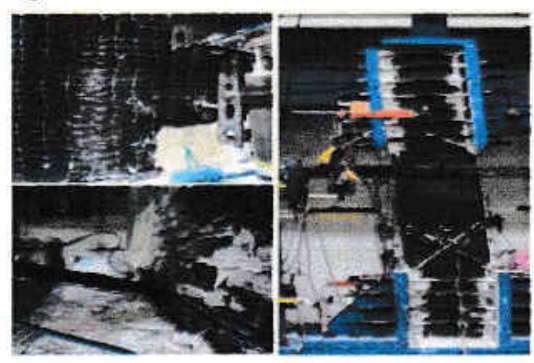

Gambar 8. Kerusakan kolom retrofit CFRP

\section{Kesimpulan}

Dari hasil analisa dan pembahasan dapat disimpulkan beberapa hal antara lain:

1. Kerusakan kolom uji terjadi pada daerah sendi plastis yang dimulai dengan terjadinya retak, spalling dan kemudian kolom mengalami keruntuhan. Untuk kolom yang dilakukan perbaikan dan perkuatan dengan material FRP proses kerusakan dimulai dengan adanya debonding material FRP dengan beton yang ditandai adanya gelembung, dilanjutkan serat putus, robek dan kemudian kolom mengalami hancur.

2. Terjadi peningkatan kapasitas lateral antara kolom yang telah diperbaiki dan diperkuat dengan material FRP dengan kolom kontrol tanpa perkuatan masing-masing sebesar $143,95 \%$ dan $152,15 \%$ masingmasing untuk kolom retrofit GFRP dan CFRP.

\section{Daftar Pustaka}

Badan Metereologi, Klimatologi dan Geofisika. "Indonesia Rawan Gempa Bumi dan Tsunami" https://inatews.bmkg.go.id/new/abo ut_inatews.php?urt=3

Departemen Pekerjaan Umum, Badan Penelitian dan Pengembangan Pekerjaan Umum, Pusat Penelitian dan Pengembangan Permukiman, (2004), "Pedoman Pemeriksaan Awal Kerusakan Bangunan Beton Bertulang Akibat Gempa" Bandung.

Park, R and Paulay, T., (1975), "Reinforced Concrete Structures" John Wiley and Sons, Canada. 
Prosiding Seminar Nasional Aplikasi Teknologi Prasarana Wilayah IX (ATPW),

Surabaya, 02 Juni 2016, ISSN 2301-6752

Pawirodikromo, W., (2012),

"Seismologi Teknik \& Rekayasa

Kegempaan" Pustaka Pelajar,

Yogyakarta.

Tavio; Achmad, K.; Parmo; and Sulistiawan, A., (2013), "Strength and Ductility of $R C$ Columns Retrofitted by FRP under Cyclic Loading," Proceedings of the 4th International Conference on Applied Technology, Science, and Arts (APTECS-IV 2013), 10 Dec. 2013, Sepuluh opember Institute of Technology (ITS), Surabaya, Indonesia.

Tim Revisi Peta Gempa Indonesia. (2010) "Ringkasan Hasil Studi Tim Revisi Peta Gempa Indonesia $2010^{n}$ Bandung. 